Journal of World Architecture

Review Article

\title{
Discussion on Anti-seepage Wall and Anti-seepage Technology of Water Conservancy Project
}

Jie Tao $^{1 *}$, Qingpo Wang ${ }^{2}$

${ }^{1}$ Yellow River Survey and planning design and Research Institute Co., Ltd., Zhengzhou 450003, Henan Province, China;

${ }^{2}$ Henan Branch of construction administration bureau of middle route of South to North Water Diversion Project, Zhengzhou 450018, Henan Province, China

\begin{abstract}
The water infiltration problem of water conservancy projects is one of the more common problems in the construction of water conservancy projects, which seriously affects the overall construction quality and safety of water conservancy projects. This article studies the causes of water infiltration in water conservancy projects and introduces related antiseepage technologies, hoping to be a reference for the implementation of anti-seepage projects. Through research, it is found that the factors that cause water infiltration in water conservancy projects include water conservancy project structural changes, environmental factors and construction factors. Relevant personnel can use concrete anti-seepage wall construction technology and high-pressure jet grouting technology to do the relevant anti-seepage work of water conservancy projects.
\end{abstract}

Key words: Water conservancy project; Anti-seepage technology; Anti-seepage wall

Publication date: September, 2020

Publication online: 30 September, 2020

*Corresponding author: Jie Tao,1515725871@qq.com

\section{Introduction}

Due to the development of my country's national economy and the improvement of the level of science and technology, in the construction of domestic public projects, especially in the planning and construction of water conservancy projects, how to do a good job of waterproof and infiltration has attracted attention at all levels. The construction of water conservancy projects is of great value for the rational use of our water resources and the improvement of the quality of life of the people. In the context of the overall progress of modern science and technology, how to adopt active and effective technical methods to optimize and transform water conservancy projects has become one of the priorities of the relevant personnel.

\section{Significance of water conservancy project seepage prevention work}

China's water resources are generally abundant. However, due to differences in climate and other factors in different regions, the distribution of water resources is uneven. Excellent construction of water conservancy projects can ensure the reasonable allocation of water resources and ensure that residents in various regions make full use of water resources. In addition, water conservancy projects can play a role in flood control and drought resistance. In the construction of water conservancy projects, the biggest impact on the quality of water conservancy projects is water infiltration, and water infiltration problems are also very common. The construction of water conservancy projects is generally common in mountainous areas. The most important factor affecting the quality of water conservancy projects is the structure of the mountainous areas. For example, in the construction of water conservancy projects in mountainous areas, if there is no effective anti-leakage construction technology support, serious leakage will occur in the water conservancy project, which directly affects the stability of the water conservancy project construction and its future operation and use. At the same time, the quality of 
integrated water resources management is reduced and water resources are wasted. In addition, water conservancy projects lacking leak-proofing projects cannot give full play to the flood resistance and drainage efficiency in the rainy season, cannot achieve flood control, and will threaten the life and property safety and economic safety of downstream residents. With the development of science and technology in our country, the long-term development of waterproof construction technology of water conservancy projects should solve the problems according to the actual situation to ensure that the water conservancy projects play their social and economic benefits.

\section{Factors causing water seepage in water conservancy project construction}

\subsection{Structural change of water conservancy project}

In the construction process of water conservancy project, the engineering quality level is closely related to the integrity of the whole project structure. In the application of penetration protection technology, there are some connections and influences among various factors. In the construction process of a specific project, the changes of specific construction materials, construction management plan, construction site and construction technology will have an irreversible impact on the whole project structure, leading to the low efficiency of the whole water project construction. Generally, the construction site environment of water conservancy project is relatively poor. In the process of designing the construction scheme of water conservancy project, if all kinds of unfavorable factors on the construction site can not be fully considered, the construction process will be affected by various adverse construction factors, resulting in water leakage caused by structural change. Especially after the completion of large-scale water management projects, more flood control and irrigation work is needed. If the structure can not be guaranteed in the long-term operation, the engineering structure will be prone to various cracks due to low performance, which may eventually lead to water penetration and affect the application effect of leakage prevention technology.

\subsection{External factors}

The construction quality, construction schedule, and project cost of water conservancy construction projects are closely related to various external factors at the construction site, especially some environmental factors related to water conservancy construction projects outside the construction site. These will have a serious impact on the construction of water conservancy projects ${ }^{[1]}$. The application effect of the anti-seepage technology will also be affected during the construction process of the project and will not play a role, resulting in leakage in a short period of time during the construction process, thus affecting the overall construction quality and application effect of the entire project. Among the various external factors on the construction site, geological conditions and climate environment have the greatest impact. During the construction of water conservancy projects, under extreme weather such as storms, strong winds, landslides, etc., especially when a large amount of rainwater accumulates on the construction site and cannot be discharged in time, the entire water conservancy project structure and the application of safe construction technology on the construction site will cause serious problems. influences. This led to aggravation of water infiltration problems throughout the project. In addition, in the process of designing construction drawings, strict and extensive geological surveys cannot be carried out in front-line construction; the geological environment and geological changes at the construction site cannot be fully grasped; scientific drainage and irrigation channels cannot be designed based on the actual conditions of the construction site, which will make the project the external drainage capacity is impaired. In this case, the application of water leakage protection technology is difficult to play a role.

\subsection{Construction factors}

The construction of water conservancy projects is a very complex system engineering. In recent years, the construction scale of water conservancy projects has continued to expand, and the building structure has become complex. It is often necessary to coordinate different types of mechanical equipment and cooperate with the construction site for construction. For water conservancy construction projects, from project initiation to design bidding, bidding and subcontracting, project construction takes a long time. Therefore, the overall construction quality is easily affected by the construction period, construction technology and professional skills of construction personnel. In the process of water conservancy project construction, if the construction personnel have poor professionalism, fail to strictly follow the construction plan, and fail to adopt necessary leakage prevention techniques, it is easy to cause various project quality problems in the future construction or use. In addition, the construction 
sequence of the construction site is chaotic and various tasks are not coordinated, which often leads to poor construction quality, which affects seepage prevention. In the construction process of some large-scale projects and concealed projects, improper handling of connections will result in huge gaps between the structures, which will lead to areas prone to leakage after the use of the project, leading to large-scale water leakage. After the project is completed, effective repair measures cannot usually be taken for these key parts. Therefore, when constructing water conservancy protection projects, it is necessary to select appropriate anti-seepage methods according to the actual conditions of the construction site to ensure the construction quality of water conservancy construction projects.

\section{Anti-seepage technology used in water conservancy project construction}

\subsection{Drilling and slotting technology}

In the actual application of drilling and grooving technology, the division of the grooving part should be appropriately adjusted according to unfavorable factors (such as the progress of hole processing and the stability of the hole wall). For gravel, dam soil and bedrock parts, percussion drill bits can be used for drilling. At the same time, by referring to the location and depth of the main hole and the identification of the bedrock surface, the location and depth of the secondary hole can be finally determined. In the specific use and maintenance process, the type of construction technology should be selected according to various geological conditions and the type of drilling equipment.

\subsection{Concrete pouring technology}

Concrete pouring technology is the core technology of plastic concrete cutoff wall construction technology. The pouring of the cutoff wall mainly depends on the opposite pressure generated by the concrete surface inside the conduit and the slurry surface outside the conduit to form stability ${ }^{[2]}$. In the concrete construction stage, the main technology of cut-off wall construction is pouring concrete technology. In the process of construction and management, construction personnel must make full use of the good fluidity and workability of concrete itself to fill the space occupied by soil initially. It is very important to pay attention to the pouring time in the pouring process. Generally, the pouring time should be adjusted within 4 hours after drilling. In the current concrete construction process, most domestic construction units take the vertical pipe method as the main method.

\subsection{Slot hole stabilization construction technology}

Another main embodiment of the construction technology of plastic concrete anti-seepage wall in waterproof engineering is the construction technology of slot stabilization. The application of this technology in water conservancy projects can effectively prevent the gaps in concrete barrier walls from becoming unstable. During construction, trench excavation must be carried out in dry sand, and the broken surface of trench excavation must be able to form a certain angle with the plane. If there is no protective wall in the clay layer, a vertical trench excavation method is required.

\subsection{Construction technology of post-grouting pile}

Through this technology, the solidified slurry is injected into the cracks of the rock and soil foundation to realize the effective filling and compaction of the cracks, increase the strength of the entire foundation structure, effectively improve the physical properties of the foundation, and ensure the entire area Construction Quality. In the construction process of water conservancy projects, post-grouting pile construction technology is the most commonly used technology, which has the characteristics of simple operation and low investment cost. Pour the cement slurry into the preset pile to achieve the purpose of greatly improving the grouting bearing capacity, strengthening the foundation, and preventing water leakage.

\subsection{High pressure jet grouting}

High pressure jet grouting is to pour impermeable grouting into the cracks of water conservancy construction projects under high pressure conditions, consolidate its water conservancy structure, prevent water penetration and improve the quality of water conservancy construction projects. When using high pressure jet grouting method, rotary shotcreting, fixed shotcreting and swing shotcreting can be used to ensure water conservancy construction projects to prevent water leakage. High pressure jet grouting has the function of strengthening and preventing water leakage. According to the actual water leakage situation of water conservancy projects, high-pressure jet grouting technology can be selected to enhance the integrity of water conservancy projects ${ }^{[3]}$. High pressure jet grouting technology can be used to effectively penetrate the finished structure or subgrade. The technology takes up a small building area in the process of strengthening and preventing the foundation leakage, and the surface structure of the foundation is not destructively treated. 
The whole operation is flexible and simple, and the operability is strong. Compared with the traditional deep mixing method of leak proof technology, this method has wide adaptability and can adapt to various geological environments, especially the foundation with low water content.

\subsection{Multi head deep mixing cement method}

The multi head deep mixing cement method mainly uses the multi head probe deep mixer to homogenize the cement and soil, and after the fusion, the uniform cement and soil will form cement soil pile. The cutoff wall is the overlap of these cement and soil piles. The engineering cost of the multi head deep mixing cement method is not high, and the construction is relatively simple.

\section{Conclusion}

In short, the construction of water conservancy projects to prevent water seepage treatment is very important, which directly affects the quality and operation efficiency of water conservancy projects. In order to ensure the actual efficiency of anti-seepage engineering in water conservancy construction projects, it is necessary to combine the requirements of water resources management engineering construction and the current situation of water resources management engineering construction to scientifically and reasonably carry out engineering construction, so as to ensure the quality of the project, analyze in detail the basic factors affecting the anti-seepage ability of water conservancy projects, adjust various target indexes, and use advanced science and technology to make China The construction technology of water conservancy projects is constantly improved to maximize the economic and social benefits of water conservancy projects.

\section{References}

[1] Bai FW. (2018).Study on the application of anti-seepage technology in water conservancy project construction $[\mathrm{J}]$. Modern property (zhongxunzao), (2): 152

[2] He ZJ.(2017) Application of plastic concrete cutoff wall construction technology in reinforcement project of Lianghekou reservoir in Taoyuan County [J]. Building materials and decoration(17): 283-284

[3] Yue SL, Li DD. (2019). Analysis on seepage prevention construction technology of water conservancy dike [J]. Henan water conservancy and south to North Water Diversion, 22(3): $152-153$ 